\title{
استخدام سلم التقدير اللفظي كتقويم بديل في تعليم مهارات اللغة العربية بالجامعة
}

\author{
Burhan Yusuf Habibi \\ Email: burhanyusufhabibi@gmail.com \\ جامعة سلاتيجا الإسلامية الحكومية
}

\begin{abstract}
Penelitian ini bertujuan untuk mengetahui konsep, langkah-langkah dan model evaluasi alternatif pembelajaran kemahiran berbahasa Arab di perguruan tinggi dengan menggunakan rubrik penilaian. Penelitian ini menggunakan pendekatan deskriptif analitis. Hasil dari penelitian ini menunjukkan bahwa rubrik penilaian merupakan bentuk evaluasi alternatif yang tepat dalam mengukur kemampuan mahasiswa melalui performance, kemahiran dan produk yang mereka hasilkan secara terukur, objektif dan berdasarkan pada kriteria yang jelas. Langkah-langkah dalam menyusun rubrik penilaian yaitu dengan menentukan kemahiran, performance maupun produk yang harus dimiliki mahasiswa, menentukan kriteria-kriteria penilaian, dan menentukan level atau tingkatan kemampuan mahasiswa berdasarkan criteria yang sudah ditentukan. Selain itu, penelitian ini mengungkapkan adanya model-model rubrik penilaian berdasarkan empat kemahiran berbahasa Arab, yaitu istimâ' (mendengar), kalâm (berbicara), qirâ'ah (membaca), dan kitâbah (menulis).
\end{abstract}

Kata kunci: Rubrik Penilaian, Evaluasi Alternatif, Kemahiran Bahasa Arab

\begin{abstract}
This study aims to find out the concept, steps and models of alternative evaluation of Arabic proficiencies for university students by using assessment rubric. This study uses analytical descriptive approach. The results of this study indicate that the assessment rubric is an appropriate form of evaluation in measuring the students proficiencies through the performance, skills and products that they bring about in a measurable, objective and based on clear criteria. The steps in preparing the assessment rubrics are by determining the skills, performances and products that must be mastered by students, determining the criteria of assessment, and determining the level of student proficiencies based on predetermined criteria. In addition, this study reveals the existence of rubric assessments models based on four Arabic proficiencies, which are: listening (istimâ'), speaking (kalâm), reading (qirâ'ah), and writing (kitâbah).
\end{abstract}

Keywords: Assessment Rubric, Alternative Evaluation, Arabic Proficiencies

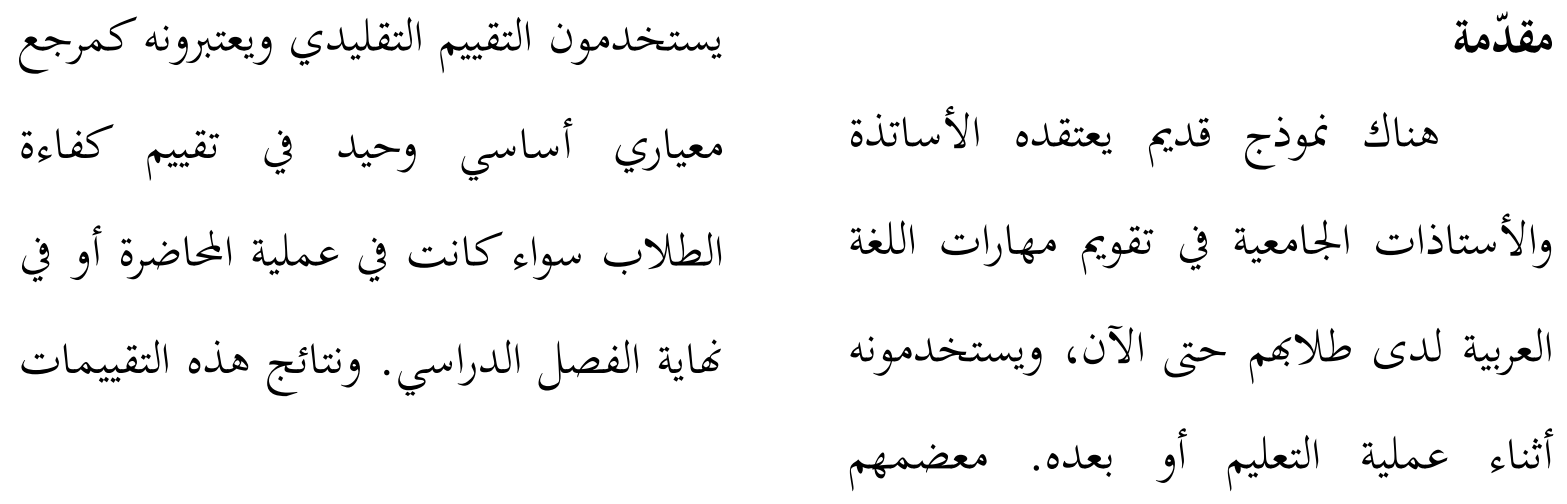


لديهم، فإن لك يتطلب استراتيجيات متنوعة للتقويم ونماذج وأدوات للحصول على المعلومات وبالتالي فإن وجود نمط واحد من التقويم لا يكفي للقيام بهذا الدور المتعدد الجوانب.

نتائج تعلم الطلاب ليست في المجال المعرفي فحسب، وإنما هو في المجال الوجداني والحركي أيضا. فالتدريب الوظيفي الذي يعطي الأولوية للمهارات والأداء ليست مناسبة إذا كان تقييم نتائج تعلم الطلاب باختبار من خلال الأسئلة المكتوبة. والتقييم التقليدي لا يلمس الجوانب التي تحتاج إلى تقييمها في عملية التعليم، مثل المهارات أو المنتجات التي صنعها الطلاب، لذلك هناك حاجة ماسة إلى بدائل أخرى لاستكمال تلك العيوب. والإجابة على هذه المشكلة هي تقييم حقيقي أو تقييم بديل مصمم لقياس المعايير التي يمكن قياسها قياسا موضوعيا واضحا.
التقليدية تسهم عالية جدا إلى التقدير النهائي للطلاب.

يرتكز التقويم التقليدي على الاختبارات بمختلف صورها، ويُعطى مرة واحدة أو عدة مرات في في العام الدراسي بغرض الحصول على معلومات عن تحصيل الطلبة لتقديمها لأولياء الأمور وغيرهم من المعنيين، ومثل هذا التقويم لا يؤثر بصورة إيجابية في التعليم، لأنه يقيس مهارات ومفاهيم بسيطة يتم التعبير عنها بأرقام لا تقدم معلومات ذات قيمة عن تعلم الطالب، و لا يمكن من خلالها تحديد نتاجات التعلم التي أتقنها الطلبة، والطلبة في التقويم التقليدي هم محور التقويم ولكنهم لا يشاركون في تقويم انفسهم ، ونتيجة للتطور أصبح مفهوم التقويم أكثر شمولاً، وأصبح للطالب دوراً هاماً فيه، ونظراً لأن التقويم يأخذ بعين الاعتبار مشاركة المجتمع وأولياء الأمور ومراقبة تعلم الطلاب وتعليمهم وفهم احتياجاتم ومواطن القوة 
الأنشطة. ومن أمثلة استخدام سلم التقدير اللفظي هو في تقييم كتابة المقالة العلمية، أو التقديم الشفوي من الطلاب أو منتجاتم وأداءهم في المحادثة العربية أو قراءة النصوص العربية وغير ذلك. وتقييم جودة الكتابة مثلا يميل إلى أن يتغير وفقا للمعايير التي يضعها كل مقيم. ويمكن أن يكون المقيم أكثر تركيزا على قواعد الكتابة، والآخر قد يكون من حيث الجدل والمضمون في الكتابة. ومع تطور مخططات التقييم السابقة لعملية التقييم، فإن الموضوعية الذاتية للمقيمين المعنيين ستكون أكثر موضوعية. فبهذا سيعرف الطلاب قدر كفاءاقم ومهاراهم الحقيقية ويساعد الطلاب في تحديد خطواته التالية في

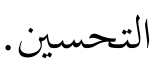

الإطار النظري

\section{مفهوم التقويم البديل}

دعت التوجيهات الحديثة في بجال

التقويم التربوى إلى نوع من التقويم يعرف

بالتقويم البديل، ذلك التقويم الذى يعتمد على الافتراض القائل بأن المعرفة يتم تكوينها
يتم التقييم الأصيل من خلال المراقبة

المنهجية المباشرة، وتقييم تحقيق هدف

تعليمي. في كثير من الأحيان، تتم المراقبة بشكل مستمر على مدى فترة من الزمن، وعلى وجه الخصوص هذا التقييم يتعلق بإنشاء منتجات من الطلاب. وقد يكون التقييم بشكل تفاعل مستمر بين المحاضرين والطلبة، ويكون من الناحية المثالية جزءا من عملية التعليم. يجب أن يكون التقييم أداءا للواقع الذي يتصل بمجتمع الطلاب وبيئتهم. وسلم التقدير اللفظي هو واحد من أدوات التقييم الأصيل أو التقييم البديل الذي يمكن به قياس قدرة الطلاب على أساس أدائهم ومنتجاةم. سلم التقدير اللفظي هو مخطط تقييم وصفي الذي يمكن استخدامه كمعيار تحليل المنتج والأداء أو عملية التعلم ونجاح الطلاب في تعليم مهارات اللغة العربية. ويستخدم هذا

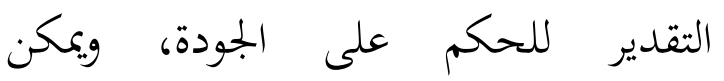
استخدامه أيضا لتقييم مختلف المواضيع أو 
المتكاملة للمتعلم عبر الزمن. وسبق ان بين مكسيموس بأن التقويم البديل هو تقويم واقعي للأداء بصورة تعكس المستوى الفعلي لما تم تعلمه. وأطلق على هذا النؤع من 'التقويم، اسم التقويم الأصيل ، وأحياناً التقويم الواقعي، والتقويم الشامل، والتقويم القائم على الاحكام، والتقويم المباشر، والتقويم الطبيعي. وقد اورد علام المصطلحات أو المفاهيم المرادفة لمفهوم التقويم البديل ومنها:التقويم الاصيل؛ والتقويم القائم على الأداء، والتقويم البنائي، والتقويم الوثائقي، والتقويم الكيفي، والتقويم المباشر.

يعد التقييم البديل في الجامعات

$$
\begin{aligned}
& \text { r محمد السيد علي، "ابحاهات وتطبيقات }
\end{aligned}
$$

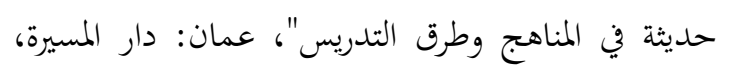

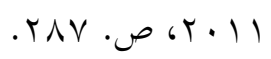

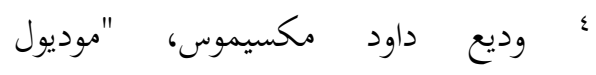

$$
\begin{aligned}
& \text { استراتيجيات التدريس والانشطة، مشروع تطوير برنامج }
\end{aligned}
$$

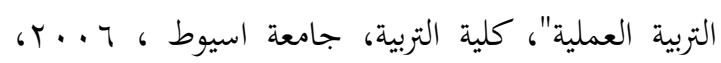

$$
\begin{aligned}
& \text { ص. } \\
& \text { • صلاح الديد محمود علام، " التقويم التربوي }
\end{aligned}
$$

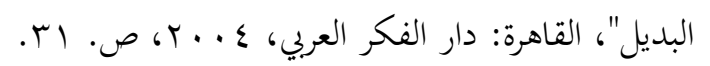

وبنائها بواسطة المتعلم، حيث تختلف تلك المعرفة من سياق لآخر وتقوم فكرة هذا النوع من التقويم على إمكانية تكوين صورة متكاملة عن المتعلم فن ضوء مجموعة من البدائل بعضها أو جميعها. والتقييم البديل هو تقييم غير تقليدي يقيم عملية اكتساب وتطبيق المعارف والمهارات التي تثبت قدرة الطلاب على العمليات والمنتجات. التقييم البديل قادر على تسهيل الطلاب لإظهار معرفتهم وتنوع ذكاءهم بطرق مختلفة. يرى علي بأن التقويم البديل هو متصل من الأساليب أو الصيغ التي تتراوح بين استجابات بسيطة مفتوحة يكتبها المعلم، وتوضيحات شاملة، وبحمعات من الأعمال

' سوسن شاكر مجيد، أهمية استخدام التقويم

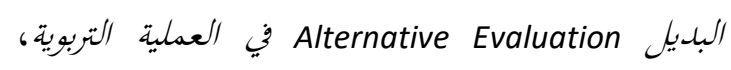

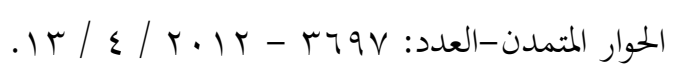

2 Nuansa Bayu Segara. Penggunaan Rubrik sebagai alternative assesment pada mata kuliah seminar studi sosial, Edunomic, Vol.2, No.2, 2014, hlm. 64. 
الواقعي المرتبط بحياة الطلاب وواقعهم، وليس بجرد استرجاع حقائق ومعلومات منعزلة عنها. يتم تلقينها داخل غرفة الدراسة، كما أن هذا التقويم يطلق عليه التقيم البديل لأنه يستخدم بديلاً عن أسلوب التقويم التقليدي الذي يعتمد على اختبارات تحريرية باستخدام القلم والورقة، وبذلك لا أرى أن هناك فصلا بين المفاهيم المرادفة للتقويم البديل، فجميعها يؤكد على أن لا تكون اختبارات الورقة والقلم هي الأساس.

ولماذا إجراء تقييم بديل الذي يتطلب الكثير من الوقت والجهد لإعداده من أمر ضروري؟ على الرغم من أن الاختيار من متعدد قد تكون مؤشرات صالحة أو متوقعة للأداء الأكاديمي، ولكن غالبا هذا الاختبار يصرف انتباه المعلمين والطلاب عن نوع المهارات التي يجب على الطلاب إتقاها. المعايير ليست قياسية، وبنود الأسئلة ليست المشكلة الحقيقية، والإجابة الصحيحة ليست
الإندونيسية من أنواع التقييم لقياس أو تقييم نتاجات تعلم الطلبة غير الاختبار التقليدي المعياري الذي يستخدم معايير تقييم معينة، مثل التقييم المعياري الذي يمدد درجة النجاح قبل الاختبار، أو تقويم القيم المرجعي الذي يحدد درجة النجاح بعد الاختبار، والذي يستخدم متوسط الطبقة على المنحنى العادي. كل من هذين التقييمين يستخدم اختبار المقال والاختيار من متعدد، أو نوع أسلوب التقويم المشهور باختبار الورقة وقلم الرصاص. كل من تلك الاختبارات يتكون من الأسئلة للطلاب التي كانت إجاباتما الصحيحة موجودة وبجهزة من قبل. وبناء على ما سبق فإن التقويم البديل و (alternative assessment) هو الأسلوب الذي يعطى من خلاله الطلاب نشاطات ومواقف تعليمية ويكلفون بأداء مهام وتكليفات تتشابه إلى حد كبير مع مواقف الحياة اليومية وما يتم تقيمه هو الأداء 
التقليدي كافيا. ولكن إذا كان الهدف من

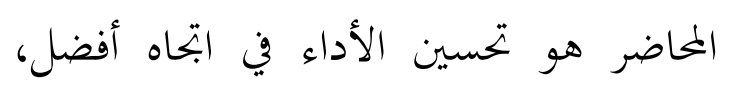
فالأحسن أن يتكون الاختبار من الواجبات التي تمكن أن تكون أمثلة ومواصفات ومعايير.

\section{أهمية التقويم البديل}

يتميزّ التقويم الواقعي بأنه يرّزّ على بلى

المهارات التحليلية، وتداخل المعلومات كما

أنه يشجع الإبداع ويعكس المهارات الحقيقية في الحياة ويشجع على العمل التعاوني، وينمي مهارات الاتصال الكتابية والشفوية كما أنه يتوافق مباشرة مع أنشطة التعليم ومنتجاته

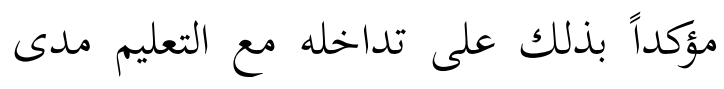
الحياة كما أنه يؤمن بدمج التقويم الكتابي والأدائي معاً، ويعتمد على القياس المباشر

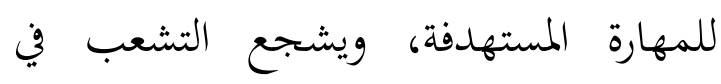
التفكير لتعميم الإجابات الممكنة، ويهدف إلى دعم تطوير المهارات ذات المعنى بالنسبة
هي الأساس المنطقي. أولئك الذين يحافظون على الاختبار التقليدي لا يرون هذا النموذج لحن

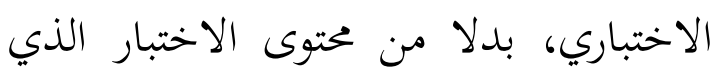
يضر عملية التعلم. يشعر الطلاب بأن التعلم خانق، ويعتقد المحاضرون أن الاختبار هو باحث الحقائق، مع أنه يتكون من بجموعة

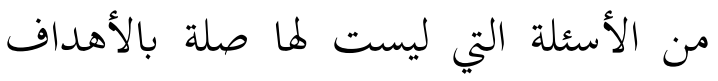
ونجاح تعلم الطلاب. يقاد كل من المحاضرين والطلاب إلى الاعتقاد بأن الجواب الصحيح

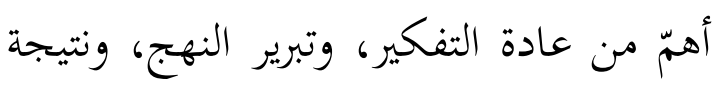
العمل لشخص.

ومما سبق، يتضح أن اتباع منهج التقييم الذي ينظر إلى الواجبات والنتائج الواقعية يمكن أن يهسن عملية التعليم والتعلم،

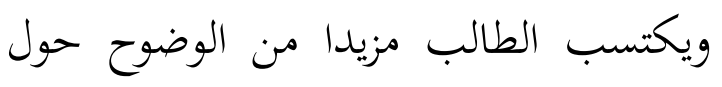
التزاماتم، ويعتقد المحاضرون أن نتائج التقييم أكثر وضوحا وأكثر فائدة في تحسين عملية التعلم. وإذا كان الهدف من المحاضر هو فقط لمراقبة أداء الطلاب، قد يكون الاختبار 


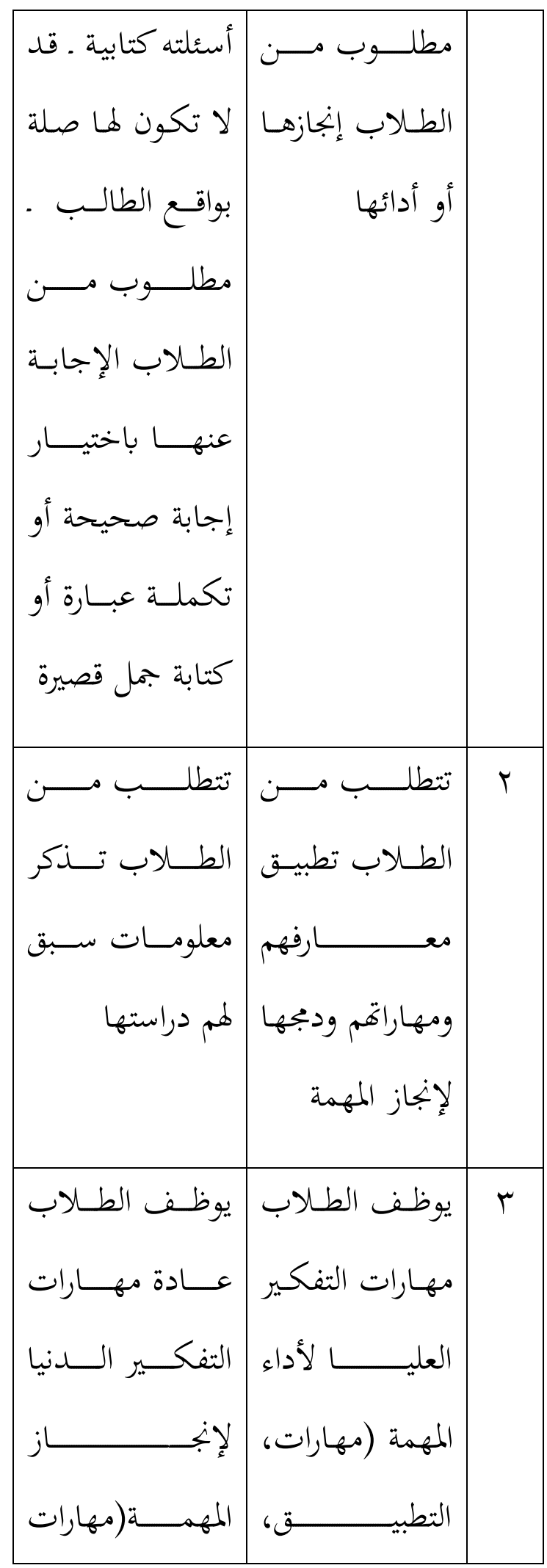

للمتدرب، ويوجه المنهج، ويركز على الوصول إلى إتقان مهارات الحية الحقيقة ويدعم المعلومات التي تعنى بـ ( كيف )، ويوفر رصداً لتعلم المتدربين على مدار الزمن، ويُعد المتدرب لمعالجة الغموض والاستثناءات التي توجد في أوضاع حقيقة للمشكلات، ويعطي الأولوية لتسلسل التعلم أو عمليات التعلم. ويختلف التقويم البديل والتقويم التقليدي من عدة أوجه التي من أبرزها ما هو موضح في المخطط الآتي: جدول المقارنة بين التقويم البديل والتقويم v

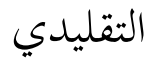

\begin{tabular}{|c|c|c|}
\hline التقويم التقليدي & التقويم البديل & الرقم \\
\hline يأخــــــــ شـــــكل & يأخــــــ شــــكل & 1 \\
\hline اختبــار تحصــيلي & مهـــام حقيقيـــة & \\
\hline
\end{tabular}

v ثان حسين خاجي، "اسهامات استرابتيات

التقويم البديل (Evaluation Alternative) في تحسين

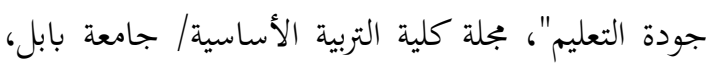

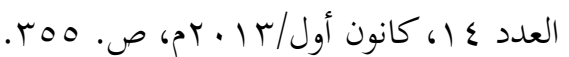




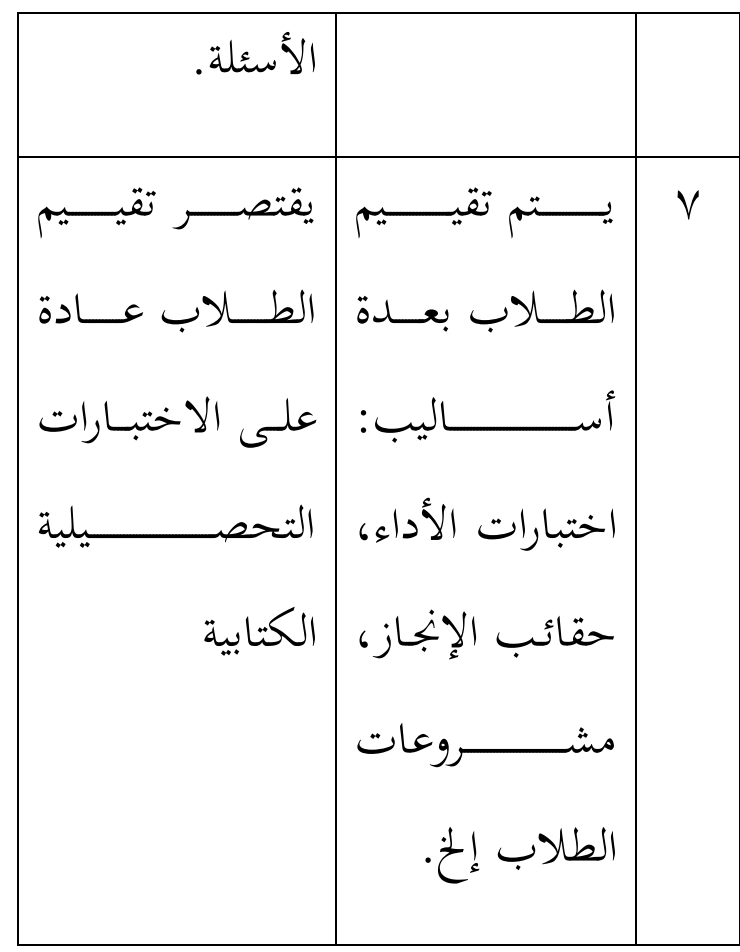

ويشير جابر بأن التقويم البديل له فوائد عدة منها: ( ) يقدم للطلبة مهاماً واعمالاً مشوقة، وذات قيمة لحياتم، وهي تتحداهم لكي يطرحوا اسئلة ويصوروا أحكاماً، ويبحثوا عن امكانيات وبدائل. r براعي الفروق الفردية. ب) يكون لدى الطلبة ابجاهاً موجباً نهو التعلم. § ) يعمل على ان يكون دور المعلم مساعدة الطلبة على تحمل مسؤولية تعلمهم وان يصبحوا مقومين ذاتين. 0) يعطي دوراً اكثر نشاطا للآباء في التقويم، اذ يشجع الاباء على أن ينظروا إلى ما هو ابعد من تقديرات الاختبار والتقارير، أو الشهادات

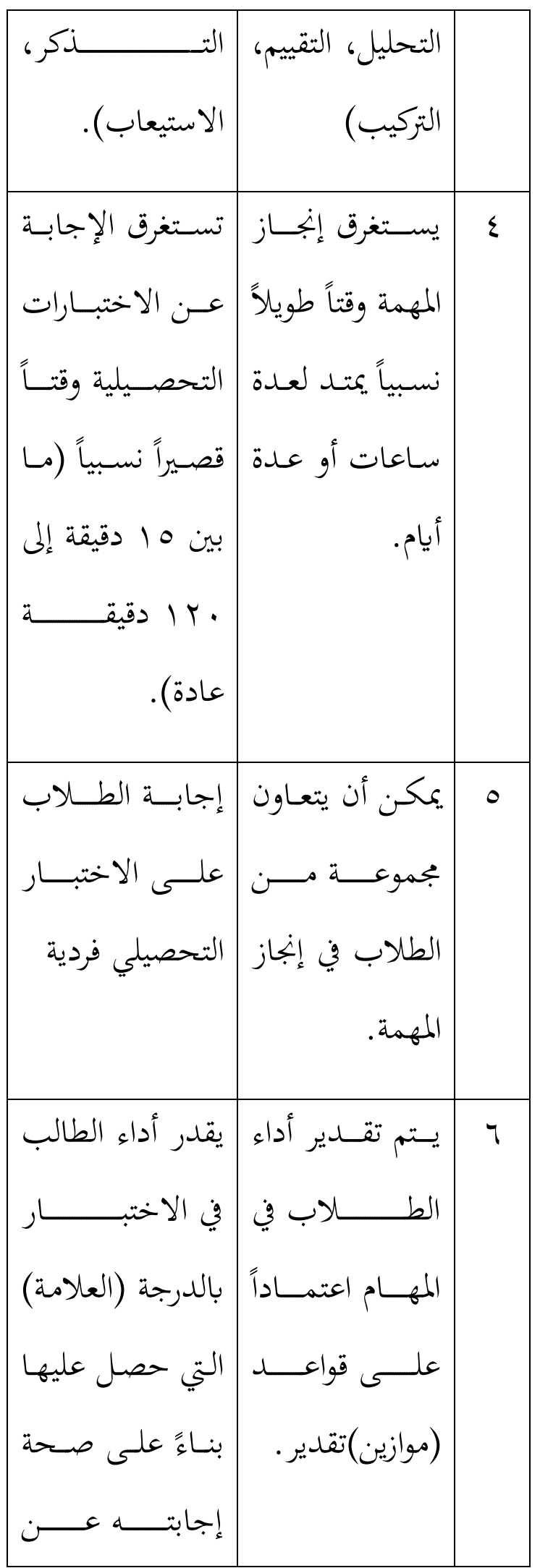


من الصفات المختصرة التي تبين أداء الطالب في مستويات مختلفة. إنه يشبه تماماً سلم التقدير، ولكنه في العادة أكثر تفصيلاً منه، مثا يجعل هذا السلم أكثر مساعدة للطالب في تحديد خطواته التالية في التحسن، ويجب أن يوفر هذا السلم مؤشرات واضحة للعمل الجيد المطلوب. ويتطلب تصميم سلم التقدير اللفظي من المعلم عندما يرغب في تقييم الأداء أن يحدد مهام الأداء فقد يكون التقويم منصباً على النشاط أثناء أداء المهمة تحقق مستويات جودة معينة، وقد يكون منصباً على تكوين نتاجات، وتُقيم استناداً إلى محكات تتضمن خصائص الجودة التي ينبغي أن تتوافر في كل منها. ففي هذه الحالات لا يكون الاهتمام منصباً على عملية ابتكار أو تكوين النتاج وإنما على خصائص النتاج

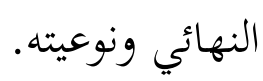

'الإدارة العامة للإشراف والتأهيل التربوي، "التقويم التربوي"، فلسطين: وزارة التربية والتعليم العالى،

$$
\text { . . . . . . . I }
$$

المدرسية في تقويم إنجاز الطلبة وتحصيلهم. كما لخصت الخرابشة أهم فوائد التقويم الخيم البديل بالآتي: 1) يركز على توثيق نمو الئه الطالب الفردي بكرور الوقت بدلا من مقارنة

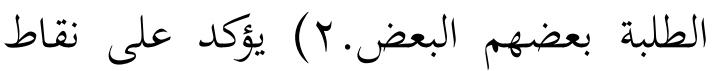
القوة لدى الطلبة بدلا من التركيز على نقاط التطاط ضعفهم. r) يستند على علد من مصادر المعلومات المثنوعة، وليس على الاختبارات فقط. ويككن ان تكون تقوية"عملية التواصل بين المدرس والطالب احدى فوائد التقويم البديل والتي تسهم في تشخيص نقاط الضعف لدى الطالب ومعالجتها في الوقت المناسب وتعزيز الحالة الايجابية لديه. سلم التقدير اللفظي يعرف سلم التقدير اللفظي بأنه أحد استراتيجيات تسجيل التقويم، وهو سلسلة " جابر عبد الحميد جابر، "ابخاهات وبحارب معاصرة في تقويم أداء التلميذ والمدرس"، القاهرة): دار باريد

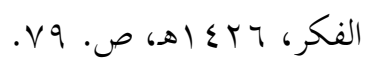
9 بنان الخرابشة، "أثر استخدام أساليب التقويم البديلة في أداء طلبة الصف التاسع الاساسي في التعبير

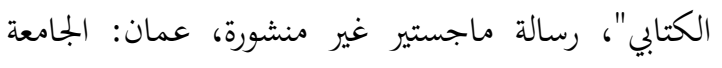

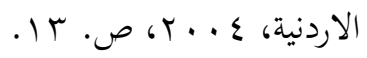


يرى ساسونغكو أن سلم التقدير اللفظي هو دليل التقييم الذي يصف المعايير التي يرغبها المحاضر في تقييم أو إعطاء مستوى نتائج عمل الطلاب. ويمتاج هذا

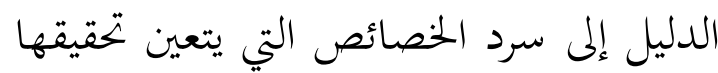
على عدة مستويات. يستخدم سلم التقدير الفظي في التقييمات الذاتية. ويتطلب إلى قاعدة لوضع المعايير في نظام التقييم الواجب اتباعه في التقييم. ويككن أن يكون سلم التقدير اللفظي في شكل وصف صريح لخصائص أداء معين على سلم التقدير. يشير سلم التقدير اللفظي بصفته الواضحة إلى جودة الأداء المتوقعة حسب سلم التقدير، أو تعريف نقطة درجة معينة

$$
\text { على مقياس سلم التقدير. }
$$

ويكن استخدام سلم التقدير اللفظي

لقياس الكفاءات المختلفة التي يمكن أن يتقنها الطلاب أثناء عملية تعليم اللغة

\footnotetext{
Nuansa Bayu Segara. Pênggunaan
}

يختلف سلم التقدير اللفظي بقوائم الرصد، ويستخدم في تقييم الأداء. تم تصميم سلم التقدير اللفظي رسميا كدليل تقييم الذي يتكون من معايير أداء محددة التي تمت تصميمها من قبل، ويستخدم لتقييم أداء الطلاب في تقييم الأداء. وعادة ما تكون نماذج البحث هي الشكل الخحدد لأداة التقييم المستخدمة لتقييم أداء الطالب أو المنتج الناتج عن تخصيص المظهر. تتيح هذه الأداة للمعلم إدراج مستويات المهارة المراد تقويكها لفظيا إلى عدد من المستويات بشكل أكثر تفصيلا من سلالم التقدير، حيث يتم تحديد وصف دقيق لمستوى أداء الطلبة، مما يمكن المعلم من تزويد الطلبة بالتغذية الراجعة التي

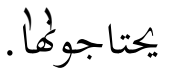

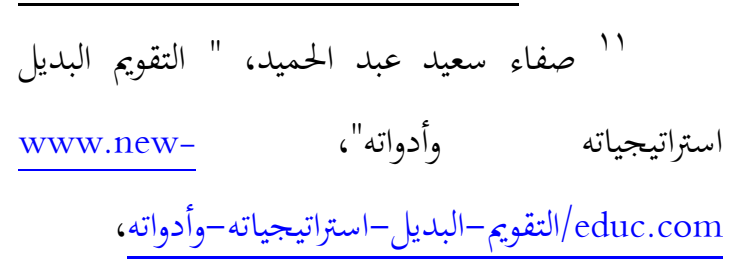
diakses tanggal 07/03/2018, Pukul 15.00 WIB. 
لاستيعاب معايير التقويم ويساعده في تصور العمل الجيد. r ) يشجع الطلبة على تقويم أعمالهم الخاصة وتقويم أعمال زملائهم باستخدام سلم التقدير اللفظي. r) يكون عمل الطالب مرتكزاً على مجموعة المعايير ويتم إعطاءه تغذية راجعة. ع) يمكن من جمع العينات أو الأمثلة من الأعمال على مختلف المستويات بهدف استخدامها في التدريس

مستقبلاً.

وخطوات تصميم سلم التقدير

اللفظي ما يلى : ( ) أشرك الطلبة في وصف وبناء تصور للعمل الجيد. r) حدد المعايير التي تمثل خصائص العمل الجيد. ب) صف مستويات الأداء المطلوب تقويمها. ع) ناقش المعايير والمستويات مع الطلبة وعدّلها إن تطلب الأمر ذلك. ه) صمم القائمة

r' الإدارة العامة للإشراف والتأهيل التربوي، "التقويم

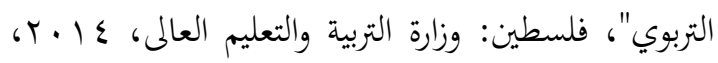

العربية، ويمكن أن تكون على شكل المهارات أو المنتجات التي ينتجها الطلاب. ومن أمثلة المهارات التي يمكن تقييمها باستخدام سلم التقدير اللفظي هي: مهارات العرض أو التقديم، والمناقشة، والمناظرة، والقراءة، والعمل الجماعي. أو أي منتج ينتجها الطلاب مثل: ورقات، وبجلات، وفيديو، وتصميم مواقع الإنترنت، وتقارير عملية وغير ذلك. لذلك يمكن أن يستخدم سلم التقدير اللفظي سلم التقدير اللفظي لتصميم عمليات التقييم إلى عملية متنوعة. وستكون الجوانب في سلم التقدير اللفظي جميعها قادرة على قياس المعايير المتوقعة من إنجاز كفاءات الطلبة. ويقلل إلى حد كبير من الموضوعية في تقييم كفاءة الطالب، حيث أن المحاضرين ليسوا مؤهلين لاستخدام العنوان فحسب، بل يمكن أن يشارك الطلاب النظراء في عملية التقييم. لسلم التقييم البديل فوائد عديدة، منها ما يلي: (1) يعطي للطالب فرصة ص. 
استخدامها في التقييم نتيجة الأبحاث السابقة النهائية بالمعايير والمستويات. التي تم اختبار صحتها، أو يمكن أيضًا إنشاء معايير جديدة مطلوبة ثم القيام باختبار صحتها. وهناك طريقة أخري سهلة لتحديد معايير سلم التقويم اللفظي وهي التصفح على الموقع الذي يوفر معايير سلم التقويم اللفظي مثل .rubricar.com. هذا الموقع يوفر معايير سلم التقويم اللفظي المجانية. ولكن يجب اختبار معايير هذا الموقع للتحقق من صحتها

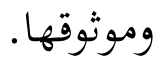

المرحلة الثالثة هي تحديد المستوى لكل معيار. ويستخدم سلم التقويم اللفظي أربعة مستويات (سلم التقدير)، وكل مستوى له نفس القيمة مع هذا المستوى. المستوى ع بقيمة ع يعني "جيد جدا". المستوى ب بقيمة r يعني "جيد". المستوى Y له قيمة ب له له معنى "كفاية". المستوى ا له قيمة | "بحاجة إلى التحسين". كل مستوى له هعاييره الخاصة.

ويرى بايو سيكارا أن لتصميم سلم التقدير اللفظي ثلاث خطوات كما يلى: الخطوة الأولى في تصميم سلم التقويم اللفظي هي تحديد الأنشطة أو المنتجات التي سيتم تقييمها. ويتم تصميم الأنشطة أو المنتجات وفقًا للكفاءة والأهداف التعليمية المرجوّة تحقيقها. ويجب أيضًا تكييفها بطريقة أو نموذج التعليم المناسب بالأنشطة والمنتجات التي يتم تقييمها بسلم التقويم اللفظي. والأنشطة التي سيتم عرضها بسلم التقويم اللفظي هي الأنشطة المتعلقة بمهارات اللغة الأربعة، وهي الاستماع والكام والقراءة

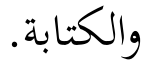
الخطوة الثانية هي تحديد معايير التقييم. ويتم تحديد هذا المعيار من قِبل مصمم سلم التقويم اللفظي وفقًا للكفاءات والأهداف والتوقعات التي يجب أن يمققها الطلبة. يمكن أن تكون المعايير التي سيتم 


\begin{tabular}{|c|c|c|c|c|}
\hline \multicolumn{4}{|c|}{ مستويات الأداء } & \multirow{2}{*}{ جوانب التقييم } \\
\hline 1 & r & $r$ & $\varepsilon$ & \\
\hline أخشأشياء & لم لم يبدي النتباهاً & ينتبه معظم & واضبدى & الانتباه \\
\hline لم لم يبدي & التياول التناءل & تفاعل & متفاعل & التفاعل \\
\hline على القد لديه & سرد بستيع & إعادة سرد & سمرديع أحداث & تلخيص المادة \\
\hline ليس لديه & يجيب & يجيب عن. & يجيب عن & \\
\hline على القدرة & أحياناً عن & الأسئلة & الأسئلة & الإجابة \\
\hline الإجابة & الأسئلة & إجابة & إجابة & \\
\hline عن & إجابة & واضحة & كاملة & الاستماع \\
\hline الأسئلة & كاملة & كاملة & واضحة & \\
\hline
\end{tabular}

\section{مناهج البحث}

استخدم الباحث المنهج المكتبي. يهدف من - لمن خلاله إلى جمع المصادر من كتب، ورسائل علمية، والسجلات، والوثائق. وذلك للحصول علي معلومات صحيحة ليستخلص منها أدلة وبراهين صحيحة يجب بها على أسئلة البحث، والمنهج لهذا البحث هو المنهج الوصفي التحليلي. ويُعتمد البحث الوصفي في هذه الدراسة للحصول على معلومات تتعلق باستخدام سلالم التقدير اللفظي كالتقويم البديل في تعليم مهارات اللغة العربية وهي الاستماع والكام والقراءة والكتابة.

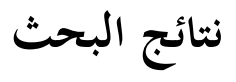

سلم التقدير اللفظي لتقييم مهارة الاستماع إن لمهارة الاستماع في اللغة العربية معاييرا وجوانب التقييم، وهي الانتباه والتفاعل عند الاستماع وتلخيص المادة المسموعة والإجابة عن أسئلة الاستماع. ولكل من تلك المعايير مستويات يمكن تصميمها في سلم التقدير اللفظي كما يلى: 


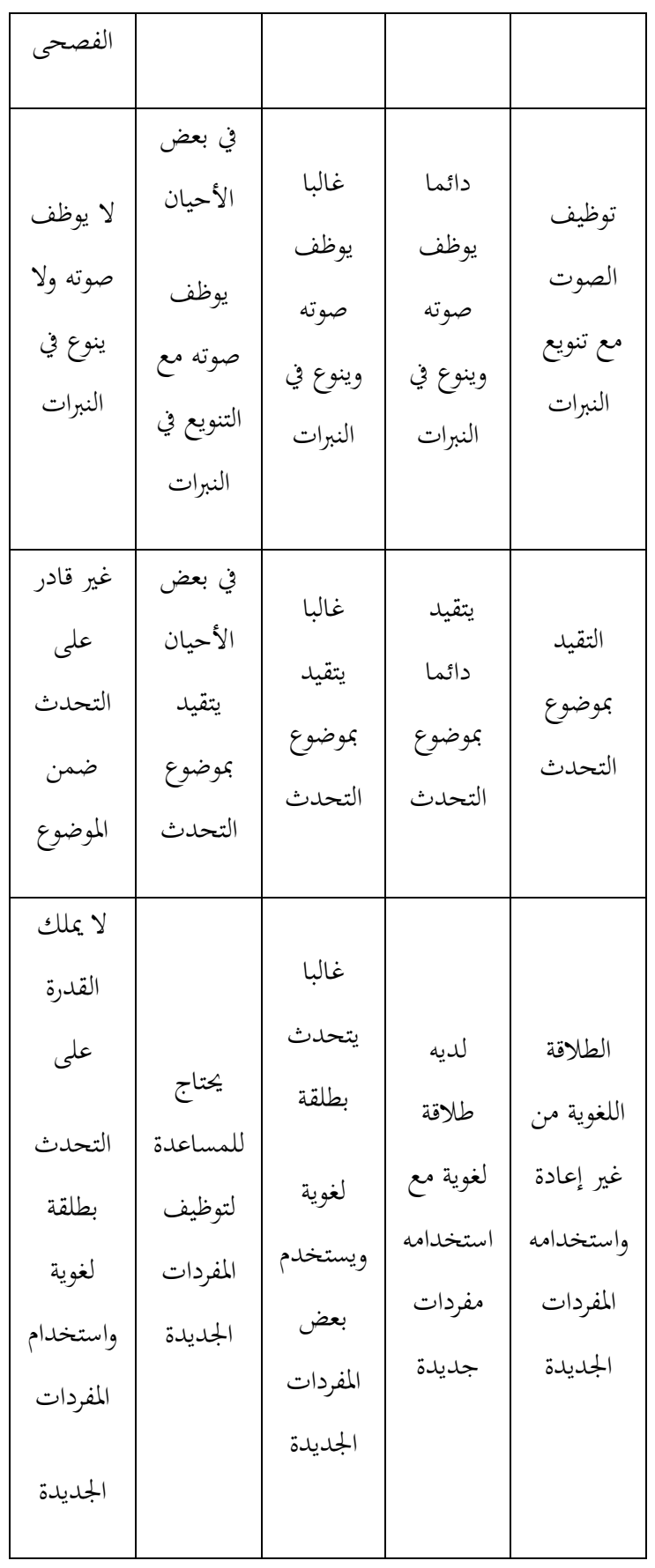

سلم التقدير اللفظي لتقييم مهارة الكلام إن لمهارة التحدث في اللغة العبية معاييرا وجوانب التقييم، وهي التحدث بثقة واضحة وجرأة، والتحدث باللغة العربية الفصحى، وتوظيف الصوت مع تنويع النبرات، والتقيد بموضوع التحدث، والطلاقة اللغوية من غير إعادة واستخدامه المفردات الجديدة. ولكل من تلك المعايير والجوانب مستويات يمكن تصميمها في سلم التقدير اللفظي كما يلى:

\begin{tabular}{|c|c|c|c|c|}
\hline \multicolumn{4}{|c|}{ مستويات الأداء } & \multirow{2}{*}{ جوانب التقييم } \\
\hline 1 & $r$ & $r$ & $\varepsilon$ & \\
\hline 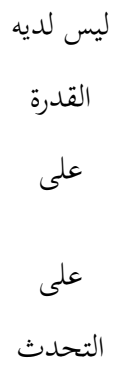 & في يتحدث & غيتحأب & التجرأة ولدقة التحدة & واضحة \\
\hline غير قادر & يتحددث & فتلغة فلباث عربية & بتحدةث & العربية الفعة \\
\hline
\end{tabular}




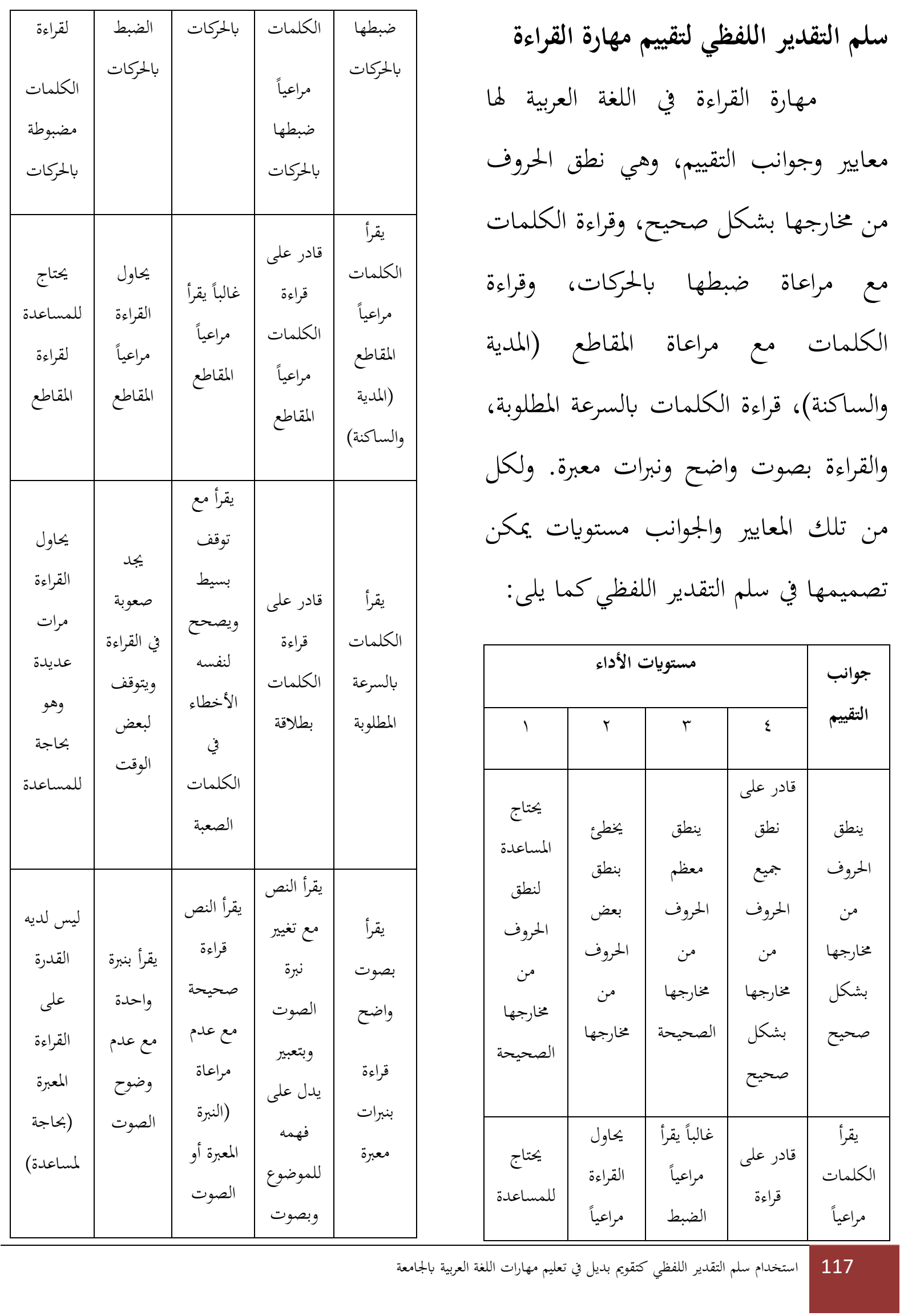




\begin{tabular}{|c|c|c|c|c|}
\hline مع مراعاة & والمقاطع & والمقركات & والمقاطع & والمقاطع \\
\hline جبداء & أكثر مقت من & أكثر مقت منتر & ليراعي & المطلوبة \\
\hline بالم رستطيع & مكر ميكا & 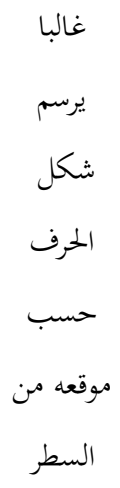 & مر مركل & رالطم شكل \\
\hline لمساعدة & 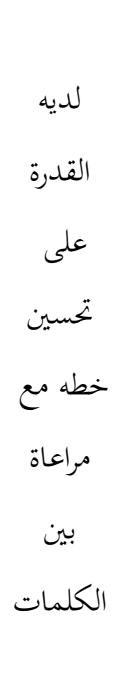 & مبك & 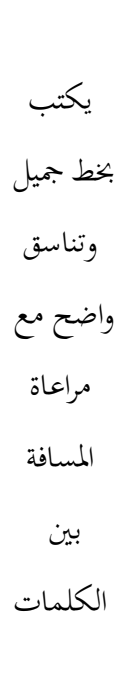 & والمالتماسق \\
\hline
\end{tabular}

\begin{tabular}{|l|l|l|l|l|}
\hline & & (اضواضح & \\
\hline
\end{tabular}

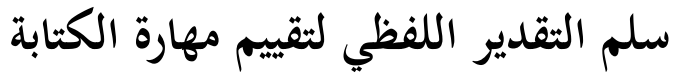

مهارة الكتابة في اللغة العربية لما معايير وجوانب التقييم، وهي بكتابة الحروف والكلمات الشكل الصحيح، ومراعاة كتابة الكلمات مع الحركات والمقاطع، والكتابة بالسرعة المطلوبة، ورسم شكل الحرف بالطريقة الصحيحة، والجمالية والتناسق ومراعاة المسافة بين الكلمات. ولكل من تلك المعايير والجوانب مستويات يكن تصميمها في سلم التقدير اللفظي كما يلى:

\begin{tabular}{|c|c|c|c|c|}
\hline \multicolumn{4}{|c|}{ مستويات الأداء } & \multirow{2}{*}{ جوانب التقييم } \\
\hline 1 & r & r & $\varepsilon$ & \\
\hline على غلى كمابر & ميخطئ فئم & أخائ أخطاء & لمالمتب & بلحكتابة \\
\hline غير قادر & أحيانا & أحيانا & دائما & مراعاة كتابة \\
\hline على كتابة & يكتب & يكتب & يكتب & الكلمات \\
\hline الكلمات & مراعيا & مراعيا & مراعيا & مع \\
\hline
\end{tabular}


التقويم اللفظي أيضا ابتكارا لعملية التعليم خلاصة سلم التقويم اللفظي هو التقويم البديل المستندة إلى الكفاءات والمنتجات والمهارات. المناسب بشكل جيد لتقييم موضوعي وقياسي لأنشطة عملية التعليم أو منتجاته. مراجع الكتابة ويتم تقييم أنشطة ومنتجات عملية التعليم البجلة العلمية مراجع المنابة

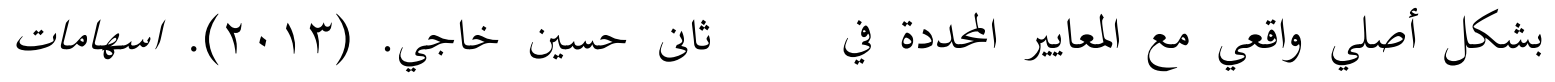

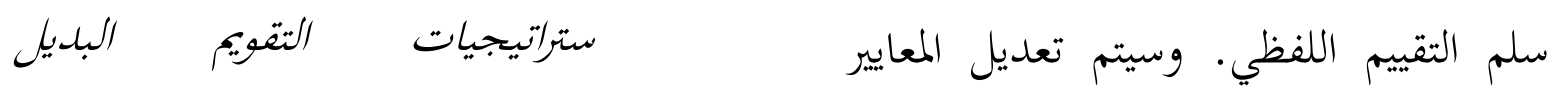
(Evaluation Alternative) المختارة بالكفاءات التي يجب أن يمقتها جودة التعليم، مجلة كلية التربية

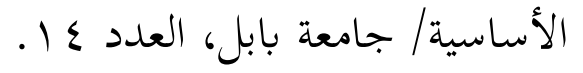
سوسن شاكر مجيد. (Y (Y. (Y). أهمية Alternative استخدام التقويم البديل الطلبة. هناك العديد من الخطوات التي يجب القيام بها في تصميم سلم التقويم اللفظي. الخطوة الأولى هي تحديد النشاط أو المنتج Evevaluation المراد تقييمه. الخطوة الثانية هي تحديد المعايير

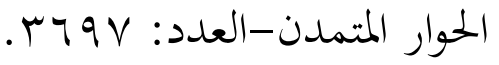

Nuansa Bayu Segara. (2014). Penggunaan Rubrik sebagai alternative assesment pada mata kuliah seminar studi sosial, Edunomic, Vol.2, No.2.

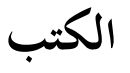

وفقا للكفاءات المراد تحقيقها. الخطوة الثالثة هي تحديد المستوى في كل معيار بجيث يكون له نطاق واضح وملائم. ويكن لسلم التقويم اللفظي من إكمال التقويم التقليدي باستخدام نموذج اختبار الورقة. إذن، لا يلزم أن يحل سلم التقويم اللفظي محل التقويم الإدارة العامة للإشراف والتأهيل التربوي.

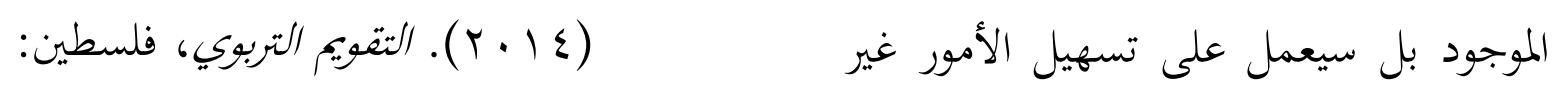
القابلة للقياس في التقويم التقليدي. ويعد سلم وزارة التربية والتعليم العالى. 


$$
\begin{aligned}
& \text { جابر عبد الحميد جابر. (TY اهـ). } \\
& \text { اتباهات وتجارب معاصة في تقويم } \\
& \text { أداء التلميذ والملدرس، القاهرة،: دار }
\end{aligned}
$$

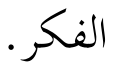

$$
\begin{aligned}
& \text { صلاح الدين محمود علام. ( ع . . ب). } \\
& \text { التقويم التربوي البديل، القاهرة: دار }
\end{aligned}
$$

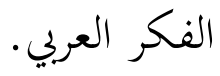

$$
\begin{aligned}
& \text { محمد السيد علي. (11 (ب). البجاهات } \\
& \text { وتطبيقات حليثة في المناهج وطرق } \\
& \text { التلدريس، عمان: دار المسيرة. } \\
& \text { وديع داود مكسيموس. (T . . Y ) موديول } \\
& \text { استراتيجيات التلدريس والانشطة، } \\
& \text { مشروع تطوير برنامج التربية العملية، } \\
& \text { كلية التربية، جامعة اسيوط. }
\end{aligned}
$$

Frans A. Rumate. (2005). Asesmen, Makasar: P3AI-UNHAS.

$$
\begin{aligned}
& \text { صفاء سعيد عبد الحميد، التقويم البديل } \\
& \text { ماتمتر|تيجياته وأدو/تهWw.new- } \\
& \text { /التقويم-البديل -educ.com } \\
& \text { •استر|تيجياته-وأدواته }
\end{aligned}
$$

